\title{
RAZÃO (PRÁTICA) E NATUREZA NA CRÍTICA DA FACULDADE DO JUÍZO ${ }^{1}$
}

Heiner F. KLEMME ${ }^{2}$

- RESUMO: Na Crítica da Razão Pura e em outros lugares, Kant apresenta uma aguda distinção entre natureza e razão prática. De acordo com Kant, não é possível deduzir ou derivar todos os sentidos dos imperativos morais dos conhecimentos empíricos sobre o mundo. Alguns intérpretes (como John MacDowell) argumentam que a concepção de razão prática em Kant pode ser ilusória se baseada em uma visão da natureza indefinida, decorrente de um ponto de vista newtoniano. Nesse texto discutirei a relação entre razão prática e natureza na Crítica da faculdade de julgar de Kant. Argumentarei que na segunda parte da obra, Kant introduz um conceito de natureza muito mais rico que as críticas lhe têm atribuído.

- PALAVRAS-CHAVE: Kant; natureza; razão; Crítica da faculdade de julgar.

Neste texto trato da relação entre razão e natureza na Crítica da faculdade do juízo. Partindo da Crítica da razão pura de Kant, fundamentado na separação estrita entre ser e dever, quero tentar entender o modo pelo qual a imagem da natureza, que Kant expõe nesta obra, modifica-se com a introdução do princípio de conformidade a fins efetuada na Crítica da faculdade do juízo. Meu interesse especial está na seguinte questão: por que, para Kant, a existência de um objeto, que por meio da faculdade de julgar reflexiva é reconhecido como um produto organizado da natureza, pode não ser simultaneamente esclarecida pelo mecanismo da natureza?

1 Uma primeira versão deste texto foi apresentada em um simpósio em Tóquio, Japão, e no III Colóquio Kant, realizado na Unesp, campus de Marília, ambos em setembro de 2008. Agradeço ao prof. Ubirajara Rancan de Azevedo Marques o convite, bem como a viabilização das condições que possibilitaram minha participação no evento brasileiro. Agradeço também à dra. Clélia Aparecida Martins a tradução do texto para o português.

2 Professor da Johannes Gutemberg-Universität, em Mainz (Alemanha). 
Na primeira parte deste texto discuto sucintamente a relação entre ser e dever na Crítica da razão pura e a concepção de Kant de juízo reflexionante na Crítica da faculdade do juízo. Na segunda parte volto-me para a relação entre mecanismo natural e teleologia natural na Crítica da faculdade do juízo e delimito a questão central de meu texto. Antes de tentar responder a esta questão, na quarta parte, na terceira retomo a solução de Kant para a terceira antinomia da Crítica da razão pura. Essa retomada serve não somente para entender melhor a especificidade da solução da "Antinomia da faculdade de julgar" (§ 69, V: 385) na Crítica da faculdade do juízo, ela também nos capacita a questionar criticamente, por trás da tese de Kant, a relação entre a consideração da natureza mecanicista e a teleológica.

\section{Ser e dever e a faculdade de julgar reflexiva}

Na Crítica da faculdade do juízo, Kant assenta a pedra fundamental para sua concepção dualista de conhecimento do entendimento baseado na natureza e conhecimento racional amparado na moral. Como seres que possuem entendimento, descrevemos (vorschreiben) a natureza externa necessariamente com leis válidas, sem com isso suprimir nossa liberdade como seres racionais. A chave para a compreensão da ligação entre natureza e liberdade é apresentada pelo Idealismo transcendental, isto é, pela doutrina da diferença entre coisa em si e fenômeno. Como sujeitos empíricos no espaço e no tempo, sujeitamos nosso querer e ação à lei da natureza, como sujeitos racionais existimos no mundo noumenal, e definimo-nos com base em nós mesmos para agir conforme a causalidade da liberdade.

Com essa concepção dualista entre mecanismo natural e liberdade, Kant escapa à crítica levantada por David Hume em seu Treatise of Human Nature (1739-49) contra o sistema racionalista moral de seu tempo. Segundo Hume, com base em princípios, é impossível expressar os fatos para inferir dedutivamente obrigações morais. ${ }^{3}$ Exatamente essa é também a tese de Kant. Com base no conhecimento dos objetos de nossa experiência, não seguimos obrigações incondicionais morais. O dever escapa tão longe de nossa atenção quanto nós consideramos a natureza na perspectiva do entendimento, porque o dever moral expressa "uma espécie de necessidade e de ligação com fundamentos",

que não ocorre em outra parte em toda a natureza. O entendimento só pode conhecer desta o que é, foi ou será. É impossível que aí alguma coisa deva ser diferente do

3 Hume, Treatise, T. 469. 
que é, de facto, em todas estas relações de tempo; o que é mais, o dever não tem qualquer significação se tivermos apenas diante dos olhos o curso da natureza. ${ }^{4}$

Na consciência do dever moral, temos um saber prático do valor necessário do mandamento da razão, ao qual nosso querer empírico põe um limite:

Por muitas que sejam as razões naturais que me impelem a querer e por mais numerosos que sejam os móbiles sensíveis, não poderiam produzir o dever, mas apenas um querer que, longe de ser necessário, é sempre condicionado, ao passo que o dever, que a razão proclama, impõe uma medida e um fim, e até mesmo uma proibição e uma autoridade. ${ }^{5}$

Entrementes, esse dever supõe que a razão pura é uma faculdade da "causalidade pela liberdade". 6

A consciência do dever moral, com isso, é para Kant a instância em que nossa liberdade como seres noumenais impele sobre a legislação da natureza, a que sucumbimos como sujeitos empíricos. Se existíssemos, contudo (como Deus), como ser puro racional, não conheceríamos o dever moral. Agiríamos com necessidade segundo a lei moral. Ao contrário, se (como os animais) existíssemos como seres puros sensíveis, definiríamos nosso querer por leis da natureza - naturalmente, neste caso um dever moral tampouco existiria. O dever moral torna-se, porém, claro por existirmos simultaneamente como seres racionais e dos sentidos. No § 76 da Crítica da faculdade do juízo, Kant esclarece a existência do dever moral pela qualidade própria de nossa razão prática com as seguintes palavras: está claro que

decorre somente da constituição subjetiva da nossa faculdade prática que as leis morais devem ser representadas como mandamentos (e as ações que lhes são adequadas como deveres). A razão exprime esta necessidade, não através de um ser (acontecer), mas sim de um dever-ser. Tal não aconteceria se a razão, sem sensibilidade (como condição subjetiva da sua aplicação a objetos da natureza), segundo a sua causalidade, por conseguinte como causa, fosse considerada, num mundo inteligível, completamente concordante com a lei moral, mundo em que não existisse nenhuma diferença entre dever e fazer, entre uma lei prática daquilo que por nós é possível, e uma lei teórica daquilo que por nós é efetivo. (V 403-404; trad. 245)

Com sua concepção dualista, Kant realmente escapa da acusação de inferir dedutivamente de um ser um dever. Questiona-se, porém, aqui se o preço que ele precisa pagar para isso não é muito alto. De acordo com a opinião de alguns autores, este preço é decisivamente muito alto. Conforme a

$4 \mathrm{KrV}$ A 547/B575. Exceto a Crítica da razão pura, todos os demais escritos de Kant são citados segundo o volume e a paginação da edição da Akademie de seus Gesammelten Schriften.

$5 \mathrm{KrV}$ A 548/B576.

$6 \mathrm{KrV}$ A 538/B566; KpV 47. 
interpretação deles, Kant pode não tornar compreensível como, por um lado, uma ação pode ser considerada livre, enquanto, por outro lado, ela é descrita como determinada por leis mecânicas da natureza. Outros críticos referem-se suficientemente a isso; para eles, Kant, com sua separação estrita entre causalidade da natureza e "causalidade da razão" (V 403; trad. 245), indica um quadro completamente consumado da natureza. Enquanto Kant, tal como Hume, afirma uma separação estrita entre fatos e valores, tem-se na realidade que a própria natureza contém significados práticos (morais e estéticos), que podemos perceber em nós. No entanto, a percepção deles assim afirma John McDowell, em seu texto Two Sorts of Naturalism ${ }^{7}$, antes de tudo, evita que nós - tal como Kant e Hume - nos orientemos por uma pré-imagem das ciências modernas da natureza, que descreve a natureza como um monte de matéria. Desmascaramos a separação estrita entre fatos e valores como um pré-juízo da filosofia do período moderno, então, segundo McDowell, podemos perceber as estruturas de significado existentes na natureza.

Busquemos as referências dessa crítica à filosofia moderna nos escritos de Kant; antes de tudo, indicamos a já citada Crítica da razão pura e a Fundamentação da metafísica dos costumes. Nelas, Kant acentua muito claramente a diferenciação entre entendimento e razão, entre causalidade da natureza e causalidade da liberdade. Retomemos nossa observação da Crítica da faculdade do juízo; tem-se pois um quadro completamente diferente da relação entre razão (prática) e natureza. Na terceira Crítica, de 1790, Kant ocupa-se com a problemática, que corresponde diretamente à crítica formulada por McDowell, sem considerar apenas ela: Kant quer demonstrar, na Crítica da faculdade do juízo, que por meio do uso do juízo de reflexão estabelecemos uma ligação entre razão prática e natureza, mediante a qual fica completo o quadro natural científico da natureza. Essa mesma razão, pois, que nos dá antecipadamente fins práticos e nos permite reconhecernos como autofim, institui o juízo reflexionante para assim julgar alguns produtos da natureza, como se (als ob) eles intencionalmente, isto é, segundo a representação dos fins, tivessem sido produzidos. Tais coisas produzidas pela "técnica da natureza", Kant denomina "produtos naturais organizados" (§ 71, V 389; trad. 230).

A "nova" imagem ${ }^{8}$ da natureza, que Kant delineia na Crítica da faculdade do juízo, supõe um conceito estendido da lei diante de seus escritos

7 McDowell, 1998.

8 No "Apêndice à Dialética Transcendental" na Crítica da razão pura, por Kant ainda não ter o conceito de juízo reflexionante, essa "nova" imagem ainda não se encontra. Enquanto em 1781 Kant ainda afirma que a razão "nunca se reporta diretamente a um objeto, mas simplesmente ao entendimento e, por intermédio deste, ao seu próprio uso empírico" (A 634/B 671), na terceira Crítica a razão concerne também ao juízo reflexionante, que, por seu lado, tem uma referência à natureza. 
antigos: ao lado da legislação do entendimento (mecanismo da natureza) e da legislação da razão (lei moral) encontra-se a legislação do juízo de reflexão. Kant quer indicar que, da perspectiva das leis constitutivas, aquele aparece como casual para a natureza, pelo que a faculdade de juízo de reflexão precisa ser compreendida como legalmente determinada. Kant denomina conformidade a fins essa "legalidade do contingente" (V 404; trad. 246). Central para a compreensão desta - paradoxal ${ }^{9}$ - "legalidade do contingente", com a qual algo em si casual é afirmado como objeto, é a relação em que o juízo reflexionante está para a razão (V 396; trad. 237). Kant define a razão como uma "faculdade de princípios" que "caminha para o incondicionado na sua existência mais extrema" (V 401; trad. 242). O princípio a priori da razão é o princípio das causas finais (V 198, 388; trad. 42 e 229). A razão indica - como já considerado - à faculdade do juízo de reflexão, coisas na natureza, que não podem ser esclarecidas pelas leis universais do entendimento, para assim julgar "como se" a conformidade a fins fosse um princípio constitutivo dos objetos da natureza. Essa exigência da razão por legalidade, isto é, por definição conceitual de todos os fenômenos da natureza, certamente não leva ao conhecimento das leis que seriam constitutivas da existência dos objetos da natureza. Ao contrário, trata-se aqui de "um princípio subjetivo da razão para a faculdade de juízo, o qual, na qualidade de regulativo (não constitutivo), é válido do mesmo modo necessariamente para a nossa faculdade de juízo humana, como se se tratasse de um princípio objetivo" (V 404; trad. 246). Trata-se de um uso regulativo, porque a conformidade a fins apresenta a regra segundo a qual a faculdade de julgar reflexiva deve julgar os objetos em sua especificidade. A faculdade de juízo reflexiva deve subsumir algo sob uma lei que ela dá a si mesma, para sua reflexão sobre as qualidades causais da natureza. Donde a conformidade a fins ser uma grandeza normativa, que se deve apenas à condição subjetiva de nossas faculdades.

Logo na Introdução da Crítica da faculdade do juízo, Kant acentua o caráter genuinamente normativo da faculdade de juízo de reflexão. Se assim se quer, a razão estende seu âmbito de objeto com a faculdade de juízo de reflexão: enquanto sua função genuína, isto é, constitutiva, existe como faculdade superior de desejar, vale para nós a lei moral, e, para motivar-nos a agir, ela refere-se à faculdade de juízo de reflexão na intenção regulativa para julgar a natureza segundo o conceito de razão da conformidade a fins. Desse modo, o princípio transcendental leva à conformidade a fins da natureza a princípios, que não dizem

9 Para a predileção de Kant pelos paradoxos, ver Klemme 2007. 
aquilo que acontece, isto é, segundo que regras é que as nossas faculdades de conhecimento estimulam efetivamente o seu jogo e como é que se julga, mas sim como é que deve ser julgado. [...] Por isso a conformidade a fins da natureza para as nossas faculdades de conhecimento e o respectivo uso, conformidade que se manifesta naqueles, é um princípio transcendental dos juízos. (V XXXI; trad. 26)

\section{Mecânica natural e teleologia natural}

Em qual relação está a conformidade a fins da natureza com a mecânica da natureza? No § 70 da Crítica da faculdade do juízo, Kant formula uma - no singular só muito dificilmente compreensível - antinomia da faculdade de juízo de reflexão (ver § 69, V 386). Essa (aparente) antinomia resulta da situação na qual a faculdade do juízo pode julgar conforme duas máximas diferentes:

A primeira máxima é a tese [Satz]: toda geração das coisas materiais e das respectivas formas tem que ser ajuizada como possível segundo simples leis mecânicas. [...] A segunda máxima é a antítese [Gegensatz]: alguns produtos da natureza material não podem ser ajuizados como possíveis segundo leis simplesmente mecânicas (o seu ajuizamento exige uma lei completamente diferente da causalidade, nomeadamente a das causas finais). (V 387; trad. 228)

Qual dessas duas máximas a faculdade do juízo deve seguir em sua reflexão sobre a natureza? Primeiramente a resposta surpreendente de Kant diz: a faculdade do juízo de reflexão pode e deve seguir ambas as máximas. Antes de tudo, ela deve seguir a primeira máxima. Pois, se o tempo todo ela não "refletir... segundo o princípio do simples mecanismo da natureza", não existiria "um verdadeiro conhecimento da natureza" (V 387; trad. 229) (por "conhecimento verdadeiro da natureza", Kant entende um conhecimento da natureza segundo os princípios do entendimento). Obviamente o "COnhecimento verdadeiro da natureza" tem seus limites. Há produtos da natureza que só podem ser compreendidos por nossa razão como necessariamente produzidos sob a retomada [Rückgriff] do princípio de conformidade a fins. Contrariamente ao que aparentam, ambas as máximas não se contradizem, pois respeitamos os limites e a especificidade da faculdade humana de conhecimento. Kant escreve:

É assim que realmente a reflexão segundo a primeira máxima não é superada, mas sobretudo somos requeridos a prossegui-la tão longe quanto se possa; também não é desse modo dito que aquelas formas da natureza não seriam possíveis segundo o mecanismo da natureza. Somente é afirmado que a razão humana, ao seguir essa máxima, deste modo nunca poderá encontrar o menor fundamento daquilo que constitui o caráter específico de um fim natural, embora certamente possa encontrar outros conhecimentos sobre leis da natureza. (V 388; trad. 229) 
A expressão "mas sobretudo somos requeridos" diz respeito à razão: não obstante a razão ter interesse em que os fenômenos da natureza sejam julgados pela faculdade de juízo de reflexão sobre sua conformidade a fins, simultaneamente, segundo Kant, ela tem interesse em que a natureza tanto quanto possível seja esclarecida com base na perspectiva do nexus efficiens. ${ }^{10}$ Em uma única passagem na Crítica da faculdade do juízo Kant utiliza para isso a expressão "necessidades intelectuais" (V 186; trad. 30).

Se podemos julgar os produtos da natureza, em princípio, com base em ambas as perspectivas causais, põe-se a questão, como ambas as perspectivas podem ser ligadas uma a outra. Fosse, pois, a mecânica completamente separada do tipo teleológico de esclarecimento, a razão, que todavia exige a unidade do conhecimento da natureza, não seria então satisfeita. Existiriam duas legislações diversas da natureza, sem acesso uma a outra. Para evitar essa "cisão" causal na estrutura da natureza e garantir a unidade de nossa experiência, Kant procura por um terceiro tipo de causalidade como a base comum de ambas. Kant encontra esse terceiro tipo no "supra-sensível":

O princípio, que deve tornar possível a unificação de ambos no ajuizamento da natureza segundo os mesmos, tem que se colocar naquilo que fica fora deles (por conseguinte também fora da possível representação empírica da natureza), mas contém o respectivo fundamento, isto é, deve ser colocado no supra-sensível e cada uma destas espécies de explicação deve ser com aquele relacionada. (V 412; trad. 253)

O supra-sensível, de acordo com isso, é o lugar noumenal no qual ambos os tipos de causalidade são pensados unidos como em um princípio. E, com sua referência ao supra-sensível, Kant não deixa dúvidas de que não pode haver solução natural à antinomia.

Embora, em razão do supra-sensível, um princípio comum de todos os esclarecimentos da natureza possa ser dado, podemos não nos referir a esse princípio, se julgarmos causais os produtos da natureza. Concluindo, o supra-sensível não nos é dado na natureza. A unificação de ambos os tipos de causalidade possível de pensar-se no âmbito do supra-sensível não suprime, portanto, sua, em princípio, incompatibilidade no julgamento dos produtos concretos da natureza no espaço e no tempo. Pois, segundo Kant, entendo uma coisa como o "produto do simples mecanismo da matéria" (§ 78, V 411; trad. 253), então fica excluído que eu possa simultaneamente esclarecer esta coisa segundo princípios de conformidade a fins. Deste outro prisma, vale que então,

10 "Interessa infinitamente à razão não afastar o mecanismo da natureza nas suas produções e não passar ao seu lado na explicação das mesmas, já que sem ele não se consegue qualquer perspiciência da natureza das coisas" (§ 78, V 410; trad. 251). 
se admito o mesmo produto como fim natural, não posso contar com uma espécie de geração mecânica do mesmo e admitir tal geração como princípio constitutivo para o ajuizamento do mesmo segundo a sua possibilidade e desse modo unir ambos os princípios. É que um tipo de explicação exclui o outro. (V 412; trad. 253)

Realmente, segundo Kant, não sabemos "até onde vai este tipo de explicação mecânica", mas não podemos afirmar com segurança que ela é insuficiente para coisas "que chegamos a reconhecer como fins naturais" (V 415; trad. 256). Por que isso assim? Porque o mecanismo da natureza não tem conceito de um objeto, no qual o todo torna possível o singular.

Como prova para sua interpretação, Kant refere-se a uma folha de erva [Grashalm]. Ele está convicto de que nunca mais existirá um Newton que possa esclarecer a existência de uma folha de erva produzida apenas pelas leis mecânicas da natureza (V 400; trad. 241). Por que não? Consideremos um outro exemplo de Kant, a saber, a anatomia de um pássaro. Pode este, por meio do nexus effectivus, ser esclarecido? Kant remete em sua resposta a um princípio universalmente reconhecido: se diz que desta anatomia

sem termos que recorrer ainda a um tipo especial da causalidade, isto é, à dos fins (nexus finalis), que tudo isto é altamente contingente [...] Isso quer dizer que a natureza, considerada como simples mecanismo, poderia ter formado as coisas de mil outras maneiras, sem precisamente ter encontrado a unidade segundo um tal princípio e por isso não seria de esperar encontrar para aquela a menor razão a priori no conceito de natureza, mas somente fora deste. (§ 62 V 360; trad. 204)

Portanto, percebemos algo na experiência, cuja existência não podemos esclarecer suficientemente com o princípio de causalidade natural. Considerado com base na perspectiva do mecanismo da natureza, permanece incompreensível, para nós, por que o pássaro tem com necessidade a característica típica dele como ser vivo. ${ }^{11}$ Devido a isso, voltemo-nos ao princípio das causas finais: a natureza mesma produz a organização do pássaro; ela quis esta organização, tal como nós humanos quando queremos atingir determinados fins. No juízo teleológico, pensamos a natureza "tecnicamente, mediante a sua própria faculdade" (§ 61, V 360; trad. 204).

De modo diferente do mecanismo natural, o juízo teleológico está sobre uma particularidade (Eigentümlichkeit) de nossa faculdade de conhecimento. No § 75 Kant escreve:

11 Em vista dos produtos da natureza, "os quais somente têm que ser ajuizados como sendo formados intencionalmente assim e não de outro modo, para que a respectiva constituição interna seja objeto de um conhecimento de experiência, aquela máxima da faculdade de juízo reflexiva é essencialmente necessária, já que até pensarmos esses produtos como coisas organizadas é impossível, sem que se ligue a isso o pensamento de uma produção intencional" (V 398; trad. 239-240. Ver também V 396; trad. 237). 
Porém o caso é completamente diferente se eu digo: a produção de certas coisas da natureza ou também da natureza no seu todo só é possível através de uma causa que se determina a si própria a agir segundo intenções; ou se digo: segundo a constituição específica das minhas faculdades de conhecimento não posso julgar de outro modo a possibilidade daquelas coisas e a respectiva produção, senão na medida em que penso para aquelas uma causa que atua intencionalmente, a qual é produtiva segundo a analogia com a causalidade de um entendimento. ${ }^{12}$

Se tivéssemos afirmado que as coisas na natureza houvessem sido causadas por um entendimento superior, então precisaríamos provar a realidade objetiva do conceito de fim. Mas isso não nos é possível. O conceito de fim não é conceito do entendimento. Se ele constituísse a natureza, ele finalmente precisaria estar na tábua das categorias da Crítica da razão pura, o que, no entanto, não é o caso. ${ }^{13} \mathrm{O}$ conceito de fim, pelo contrário, é um conceito da razão. Sua função não consiste em determinar uma categoria do entendimento conforme a um múltiplo da sensibilidade. Pelo contrário, sua função está em orientar nosso uso do juízo de reflexão: julgamos a natureza assim como se ela tivesse produzido um entendimento em conformidade a fins. A razão pura torna-se prática, no que ela define nossa vontade para agir conforme a fins; mas essa mesma razão também pode ser usada teoricamente, no que ela, pois, como razão pura prática, orienta a faculdade de juízo reflexiva a julgar a natureza como um todo conforme a fins. Com a razão pura, que, segundo a capacidade que ela define, pode ser usada praticamente (vontade) ou teoricamente (faculdade de juízo reflexiva), esclarecese como Kant pensa a passagem entre liberdade e natureza: a faculdade de juízo reflexiva é realmente (como o entendimento) uma faculdade teórica, mas ela está sob a razão pura prática, a qual conduz ao conceito de conformidade a fins. ${ }^{14}$ Em virtude de o conceito de fim constitutivo poder ser usado tão somente para a determinação legal de nossa liberdade, porém, não para o conhecimento constitutivo dos objetos da experiência, tem o "como se" regulativo tanto um sentido descritivo como normativo. Ou, de outro modo formulado: o dever da razão pura prática no âmbito do querer pode ser compreendido no âmbito da faculdade do juízo de reflexão, porém, apenas como desafio para julgar a natureza de determinado modo, e não como que, de uma hora para outra, a natureza enquanto vínculo unificador da experiência constitutiva sob o princípio de conformidade a fins. Com isso, com a razão usada praticamente no âmbito de um juízo teleológico, estendemos teo-

12 V 397-398; trad. 239. Ver outras interpretações anteriores: Förster, 2002 e 2008.

13 Ver, contra esse ponto de vista, Watkins, 2008, p. 254.

14 Para a relação entre teleologia e liberdade, ver também Guyer, 2005. 
ricamente o ser da natureza a um dever. Julgamos um produto real dado da natureza, para o que, em razão de seu fim, ele teria de dever ser.

Este dever contém uma necessidade, segundo a qual uma coisa é claramente diferente de meras leis das (sem uma idéia anterior precedente das mesmas) causas efetivas físico-mecânicas, e pode precisamente tampouco por meio de meras leis físicas (empíricas) - como a necessidade do juízo estético - ser determinada pelo psicológico, senão que exige um princípio próprio a priori na faculdade do juízo tão logo ele seja reflexionante, sob o qual está o juízo teleológico e do qual precisam ser definidas sua validade e limitação. (XX 240-241)

A interpretação de Kant sobre a origem do princípio de conformidade a fins poderia provocar em nosso espírito a seguinte objeção: por que devemos julgar um objeto da natureza de um determinado tipo, se sabemos que esse juízo não tem ganho objetivo (constitutivo) e apenas está sobre a natureza subjetiva de nossa faculdade de conhecimento? Não nos enganemos, ainda que postulemos uma unidade necessária do objeto, isto é, considerada com base na perspectiva (natural científica) do entendimento, ela não dá o objeto real? Kant talvez respondesse a essa questão do seguinte modo: nós "não observamos os fins da natureza" no objeto, "mas, pelo contrário, é somente na reflexão sobre seus produtos que pensamos ainda este conceito como um fio condutor da faculdade de juízo" (§ 75, V 399; trad. 241); não podemos, contudo, simplesmente renunciar a esse pensar. Ele é para nós subjetivamente necessário, para julgar correspondentemente, por que factualmente ordenamos sobre a faculdade de conhecimento, sobre a qual dispomos (§ 76, V 403; trad. 244). Por fim, a razão pura mesma é que exige isso de nós. A nós, como seres racionais, a natureza é sempre também um todo teleológico determinado, mesmo se os seres racionais fossem representáveis, com os quais nós pudéssemos falar sobre lógica, matemática e as leis gerais da natureza, mas não sobre a "técnica da natureza". Se prescindíssemos dessa perspectiva de julgamento, isso significaria que estaríamos renunciando a nossa razão. Mas então não seríamos mais os seres que somos.

E por que não pode ser julgado um produto organizado da natureza simultaneamente com base nas perspectivas naturais causais, se, todavia, como Kant acentua no § 78, realmente não conhecemos os limites de nossas faculdades para esclarecer de modo natural causal os "produtos e resultados da natureza" (V 415; trad. 256)? Pode-se responder a essa questão sem auxílio algum, se nos lembrarmos da solução da terceira antinomia da Crítica da razão pura, em que Kant afirma que a causalidade da natureza pode estar ligada à causalidade da liberdade. Qual é a razão para essa des-analogia entre, por um lado, causalidade da razão e mecanismo natural e, por outro, teleologia natural e mecanismo natural? 


\section{A solução da antinomia da liberdade \\ e a necessidade natural}

Na parte sobre a "Solução das idéias cosmológicas que dizem respeito à totalidade da derivação dos acontecimentos do mundo a partir das suas causas" na Crítica da razão pura, Kant afirma que "[s]ó é possível conceberem-se duas espécies de causalidade em relação ao que acontece: a causalidade segundo a natureza ou a causalidade pela liberdade" (A 532/B 560). Enquanto a causalidade da natureza vale e refere-se a todos os fenômenos que, por seu lado, a causa de cada efeito produz, indica a "liberdade, em sentido cosmológico, a faculdade de iniciar por si um estado, cuja causalidade não esteja, por sua vez, subordinada, segundo a lei natural, a outra causa que a determine quanto ao tempo" (A 533/B 561). Kant denomina essa liberdade uma idéia transcendental: conheço um objeto como a causa de um outro objeto, então conheço-o sob as condições que estão no espaço e tempo. Porque a liberdade transcendental, porém, não está precisamente sob condições empíricas, sob as quais me é dado um objeto no espaço e no tempo, nunca posso reconhecê-la como objeto de minha experiência.

Se não reconheço a liberdade transcendental como causa dos objetos que me são dados na experiência, apresenta-se naturalmente a questão, por que eu a postulo em geral, isto é, qual a razão que tenho para compreender alguns acontecimentos (Ereignisse) no mundo como seus efeitos. A liberdade prática do homem representa a chave para responder esta questão. Em virtude de o homem dispor da liberdade prática, também é preciso existir a liberdade transcendental. Enfim, segundo Kant, o homem dispõe da faculdade "de determinar-se por si, independentemente da coação dos impulsos sensíveis" (A 534/B 562).

Com essas reflexões podemos formular as seguintes alternativas: ou são efeitos primeiramente todos os acontecimentos na natureza por meio de origens naturais causais, ou há alguns acontecimentos que, em segundo lugar, são causados unicamente pela liberdade, ou, em terceiro lugar, eles são produzidos por ambos os tipos de causalidade (A 356/B 564). Para todas as três alternativas o efeito, cujas causas procuramos, é um objeto de nossa experiência. Se alguns efeitos, pois, não tivessem causas, e, por seu lado, existissem no espaço e no tempo, se refutaria o capítulo básico da Crítica da razão pura; não existira experiência comum: "A exatidão daquele enunciado, respeitante ao encadeamento universal de todos os acontecimentos do mundo sensível, de acordo com leis naturais imutáveis, já está estabelecida como um princípio da analítica transcendental e não comporta exceção" (A 536/B 564). Em todo caso, com isso mantém-se firme que não pode existir efeito na natureza que seja produzido exclusivamente pela causalidade da liberdade. Em princípio, precisa ser sempre possível conceder um 
esclarecimento natural causal. Com isso, permanece a terceira alternativa: há acontecimentos que podem ser esclarecidos por meio de ambos os tipos de causalidade? Uma resposta positiva a esta questão, segundo Kant, é possível sob uma suposição singular: se os objetos de nossa experiência fossem coisas em si mesmas, então seria a "natureza [...] a causa completa e por si só suficiente, determinante de cada acontecimento, e a condição de cada um deles está sempre contida, unicamente, na série dos fenômenos que juntamente com os seus efeitos, estão necessariamente submetidos à lei natural" (A 536/B 564). Destarte, por esses objetos serem fenômenos, eles também podem ter uma causa inteligível. "O efeito, portanto, pode considerar-se livre quanto à sua causa inteligível e, quanto aos fenômenos, consequência dos mesmos segundo a necessidade da natureza" (A 537/B 565).

Como nos representar isso concretamente? Porque a questão segundo a unidade entre natureza e liberdade só se apresenta aos homens, ela visa o status e a localização dos homens na natureza. Kant indica seguidamente que o homem, de um lado, é "um dos fenômenos do mundo sensível" (A 546/ B 574) e, com isso, sua ação está sob as leis causais da natureza. Mas, de outro lado, ele

se conhece além disso a si mesmo pela simples apercepção e, na verdade, em atos e determinações internas que não pode, de modo algum, incluir nas impressões dos sentidos. Por um lado, ele mesmo é, sem dúvida, fenômeno, mas, por outro, do ponto de vista de certas faculdades, é também um objeto meramente inteligível, porque a sua ação não pode de maneira nenhuma atribuir-se à receptividade da sensibilidade. (A 546-547/B 574-575)

Um indício de que nos representamos em nossa razão uma causalidade com base na liberdade, segundo Kant, está no fato de podermos deduzir os imperativos que expressam um tipo de necessidade "que não ocorre em outra parte em toda a natureza" (A 547/B 575). Em outras palavras, nós nos representamos a razão como uma faculdade, para de fato tornar-se causal com a liberdade, porque, e nesse ponto temos consciência disso, devemos agir de um modo determinado. Entretanto, porque dever supõe poder, é preciso nos ser possível fazer isso baseados na própria decisão (Entschluss), que devemos tomar com base em nossa consciência dos imperativos. Enquanto Kant, na Crítica da razão prática, entende que nossa consciência disso está sob determinados imperativos como um "fato da razão pura" (V 31) e dele deduz uma prova prática para a liberdade, na Crítica da razão pura ele contesta isso. De modo surpreendente:

Deverá observar-se que não pretendemos aqui expor a realidade da liberdade, como de uma das faculdades que contêm a causa dos fenômenos do nosso mundo sensível. [...] Além disso, nem sequer pretendemos demonstrar a possibilidade da li- 
berdade; nem tal se conseguiria, porquanto não se pode conhecer em geral nem a possibilidade de qualquer princípio real, nem a de qualquer causalidade, mediante simples conceitos a priori. (A 557-558/B 585-586)

Kant pensa ter demonstrado que "a natureza, pelo menos, não está em conflito com a causalidade pela liberdade" (A 558/B 586). Se a natureza não contradiz a liberdade, então ele (o homem) num certo sentido da palavra, também provou a possibilidade da liberdade. Por eu estar consciente de mim sobre isso, de determinados imperativos, a existência destes imperativos, porém, se esclarece sozinha por meio da liberdade, Kant parece, em 1781, ter indicado muito mais do que a ele prontamente coube. Daí ser estranho, em qualquer caso, a proximidade entre o acesso a esta argumentação e a doutrina do "fato da razão" na Crítica da razão prática.

Retomemos, contudo, a questão da unidade entre liberdade e natureza. Como é possível considerar uma ação produzida por meio de dois tipos diferentes de causalidade? Isso é possível porque o homem define sua ação não só como ação pelas categorias do entendimento, mas também pelo que pode considerar produzido por sua própria razão. Em último caso, diante de sua ação ele acaba defendendo um ponto de vista completamente diferente do primeiro caso: como ser racional considera-se o homem como causa noumenon, enquanto ele com suas ações precisa compreender-se determinado como ser do entendimento pelas leis mecânicas da natureza. A unidade entre ambos os tipos de causalidade, por conseguinte, concerne tão somente a suas ações, e apenas é possível sob duas suposições: primeira, que há uma diferença entre fenômenos e coisas em si mesmas e, segunda, entre entendimento e razão. Se o homem não fosse um ser racional, ele também não poderia compreender-se como autor de suas ações.

\section{A des-união entre causalidade natural e teleologia}

Com essas reflexões, podemos passar a nossa questão central: se devemos julgar nossas ações com base em duas perspectivas causais diferentes, por que então não é possível compreender um produto da "técnica da natureza" simultaneamente como um objeto produzido em sua existência natural causal? A resposta a essa questão diz o seguinte: podemos esclarecer uma ação tanto como produzida livre quanto como determinada por causas naturais, porque (1) esta ação por nós mesmos como sujeitos noumenais é efetiva, se a consideramos ação livre, enquanto (2) por meio da natureza ela é produzida, se a consideramos como determinada por causas naturais. No caso de produtos mais organizados da natureza, porém, não há dois sujeitos variados ou portadores de causalidade (o homem como ser racional e como 
membro empírico nos nexos do mecanismo da natureza), mas só um sujeito singular, a saber, a natureza. A natureza, porém, não pode simultaneamente ser ativa pela causalidade da causa final e pelo mecanismo. Para esclarecer isso, Kant escreve na "Primeira Introdução" da Crítica da faculdade do juízo:

Por ser totalmente contra as causas fisicamente mecânicas da natureza, é que a totalidade é a causa da possibilidade das partes, pois, do contrário, essas precisam ser dadas com antecedência para daí abranger a possibilidade de um todo; como logo a representação especial de um todo, a qual antecipa a possibilidade das partes, é uma mera idéia, esta, se for vista como o fundamento da causalidade, chamase fim: assim está claro que, se se dão os mesmos produtos da natureza, é impossível sua qualidade, cujas causas também apenas se investigam na experiência (para esclarecer seu papel na razão), sem ela representar-se sua forma e causalidade determinadas segundo um princípio de fins. (XX 236)

Assim, se suponho que um bicho é produto do "mero mecanismo da matéria" (§ 78, V 411; trad. 253), então a natureza pode tê-lo efetivado não em concomitância aos princípios de causa final. Por outro lado, tenho reconhecido um objeto como produto organizado da natureza, então fica excluído que este objeto tenha sido simultaneamente causado pelo mecanismo natural, mesmo se a sua existência também esteja sob leis naturais mecânicas. Estas leis são necessárias, mas não condições suficientes da existência de produtos organizados da natureza.

Entre esses princípios do juízo natural é evitado um atrito aberto, porque o juízo teleológico é meramente um "princípio heurístico" (V 411; trad. 253), ao qual sem falta precisamos recorrer por causa da natureza especial de nossa inegável faculdade de conhecimento. Destarte, como um princípio precisa se dar sua unidade, queremos poder representar-nos a natureza como "um sistema" (V 413; trad. 254). Tal unidade é possível de ser pensada por meio do "supra-sensível" já citado: "Ora, o princípio comum da dedução mecânica, por um lado, e da dedução teleológica, por outro, é o supra-sensível que temos de pôr na base da natureza como fenômeno. Deste, contudo, não podemos realizar o menor conceito definido positivamente numa intenção teórica" (V 412; trad. 253-254). Com o supra-sensível, é "menor a possibilidade" de ambos os tipos de causalidade poderem também ser unidos "objetivamente num princípio (pois concernem a fenômenos que pressupõem um fundamento supra-sensível)" (V 413; trad. 254).

Logo, na "Dialética da faculdade do juízo teleológico" o supra-sensível tem uma função diferente da coisa em si na solução da terceira antinomia da Crítica da razão pura. Enquanto o Idealismo transcendental, na Crítica de 1781, em geral torna compreensível só uma causalidade com base na liberdade, na Crítica de 1790, Kant recorre a um novo - no sentido terminológico - conceito introdutório de supra-sensível, para tornar compreensível, em 
um princípio comum, a unidade entre causalidade da natureza e causalidade final. Unicamente se o princípio da conformidade a fins representasse um princípio constitutivo, e não meramente regulador, seria excluída a busca por um princípio comum a ambos os princípios de causalidade precedentes - e inevitavelmente seria excluída a "Antinomia da faculdade do juízo".

Mas por que pode se tornar sem uso constitutivo a faculdade de juízo reflexiva, se isso, todavia, no uso prático da razão pura é o caso? Em sua resposta a essa questão, Kant, até onde lhe foi possível, referiu-se à diferença decisiva entre o uso prático da razão na determinação de nosso querer e o juízo produzido por meio da faculdade de juízo reflexiva: no âmbito de nossa ação há um "fato da razão prática". Este fato prova que a liberdade não é só possível, mas também real. Nós usamos nossa liberdade constitutivamente. Não poderíamos nos apreender como sujeitos, que se sentem ligados ao imperativo moral, se não dispuséssemos também sobre a liberdade. Duvidar que uma ação poderia ser por nós próprios causada, em decorrência, significaria retirar este fato da dúvida. Isso, contudo, não é convincente.

No âmbito dos fins da natureza é diferente. Realmente produtos organizados da natureza também são dados à nossa razão como um tipo de "Faktum"; mas esse "Faktum" desmancha-se no ar tão logo possa ficar claro que pelo uso constitutivo de nosso entendimento têm-se levantado as leis gerais da natureza. A razão pura em seu uso prático é privilegiada; ela tem uma precedência porque ela mesma produz a realidade - que ela quer. Por meio do juízo da natureza pela faculdade de juízo reflexiva, porém, esse Faktum não é produzido como objeto, apenas tentamos entendê-lo. Produção e entendimento (julgamento) são dois diferentes modos completos de nossa faculdade.

Podemos manter aqui que a des-analogia entre a antinomia na primeira e na terceira Crítica está bem fundamentada. Por certo permanece filosoficamente problemática a tese de Kant de que - como no caso da folha de erva - conhecemos produtos na natureza que não podem ser esclarecidos por meio de leis causais mecânicas. Segundo o princípio pelo qual nós, tal como qualquer outro possível produto da natureza, devemos esclarecer por meio de leis mecânicas, para evitar um "dispersar-se" da razão, deveria-se questionar se os organismos não podem ser completamente esclarecidos de modo natural mecânico. A biologia moderna seguramente respondeu afirmativamente: segundo sua opinião, nada existe de coisas vivas que não possa ser esclarecido, quanto a causas naturais, por meio dos princípios da física e da química. Logo, se as ciências modernas da vida tivessem obtido os meios do mecanismo da natureza necessários para esclarecer todos os fenômenos na natureza, não precisaríamos mais do princípio da teleologia. E seria superficial a razão que encarrega a faculdade de juízo reflexiva a 
proceder de acordo com o princípio de conformidade a fins - ou talvez, melhor dito, ela ainda seria apenas subjetiva.

Se obtivéssemos um puro esclarecimento mecanicista de todos os produtos da natureza, então o Epicuro parcialmente criticado (e não completa e seriamente considerado) por Kant (§ 74) estaria correto: o mundo é uma composição de átomos, e o acaso, um fato de nosso conhecimento da realidade. A referência de Kant à inevitabilidade de um julgamento racional da natureza, como ocorrência conforme a fins teria perdido sua força de convicção. Não necessitaríamos mais do conceito de uma causalidade que só por meio da "razão é pensável". Sucederia, pois, uma situação com a qual Kant seguramente tampouco teria contado, tal como se dá com a ofensiva que as neurociências contemporâneas exercem sobre o conceito de filosofia prática.

\section{Conclusão}

No início deste texto, referi-me ao significado da Crítica da faculdade do juízo segundo a compreensão da natureza por parte de Kant. Com e na terceira Crítica, Kant alcança um puro entendimento mecânico da natureza, e por isso ele descreve a faculdade de juízo reflexiva como uma faculdade, que, sob a retomada do conceito racional da conformidade a fins, produz os significados na natureza, os quais, considerados com base na perspectiva do entendimento, não são encontrados nela. Com a faculdade de juízo reflexiva estando sob a razão pura, vem o dever na natureza. E, com este dever, nós não alcançamos só os homens "como o último fim da natureza" (§ 83, V 429; trad. 270), cujo querer e agir nisso é mensurável se ele contribui para a realização de sua determinação naturalmente pretendida sobre a terra, mas também reconhecemos ainda que a natureza encontra no homem sua última determinação. De mais a mais, existe nisso o grande mérito de Kant de ter formulado uma concepção de fim, da conformidade a fins e da teleologia, que decisivamente se distingue da tradição antiga greco-aristotélica da teleologia: objetivamente considerada, não há conformidade a fins na natureza. Enquanto não podemos, todavia, reconhecer o ser interno da natureza, precisamos, como seres racionais, não só julgar produzidos determinados produtos da natureza como causas finais, precisamos nós mesmos nos conceber como tais seres. O homem existe como fim terminal em e para a natureza (§ 87, V 449-450; trad. 289).

Mesmo que Kant conteste isso veementemente, com sua referência a um não possível Newton da folha de erva, não está exorcizado o perigo do naturalismo mecanicista. Provavelmente, à luz dos acontecimentos que indicam ainda que somos dispensados do último bem da "essência mecânica da natureza" (V 388; trad. 230), se requer uma leitura intensiva e filosofica- 
mente interessante da Crítica da faculdade do juízo, sem precisar retomar uma ontologia implausível dos fins, tal como ela é favorecida pelo próprio cerne contemporâneo-aristotélico. Mas não gostaria de afirmar que já encontramos um tal argumento.

(Tradução de Clélia Aparecida Martins)

KLEMME, Heiner F. (Practical) reason and nature in Critique of Judgement. Trans/Form/Ação. São Paulo, v.32(1), 2009, p.55-72.

- ABSTRACT: In this Critique of Pure Reason and elsewhere Kant argues for a sharp distinction between nature and pratical reason. According to Kant, it is not possible to deduce or derive in any way moral imperatives from our empirical knowledge about the world. Some of his readers (like John McDowell) have argued that Kant's conception of pratical reason is misleading just because of his claim that nature itself is meaningless because of his mere Newtonian outlook. In my paper I will discuss the relation between practical reason and nature in Kant's Critique of Judgement. I will argue that in the second part of this work, Kant introduces a concept of nature that is much richer than critiques are willing to concede to him.

- KEYWORDS: Kant; nature; practical reason; Critique of judgement.

\section{Referências bibliográficas}

FÖRSTER, Eckart. "Von der Eigentümlichkeit unseres Verstandes in Ansehung der Urteilskraft (§§ 74-8)". In: Höffe, O. (Org.). Immanuel Kant, Kritik der Urteilskraft. Berlim, 2008, 259-274.

"Die Bedeutung von §§ 76, 77 der Kritik der Urteilskraft für die Entwicklung der nachkantischen Philosophie". In: Zeitschrift für philosophische Forschung, 56 (2002), 169-90 e 321-45.

GUYER, Paul. Kant's System of Nature and Freedom. Oxford, 2005.

HUME, David. A Treatise of Human Nature, 2 vols. Org. de D. F. Norton \& M. J. Norton. Oxford, 2007.

KANT, Immanuel. Gesammelte Schriften, ed. da Preußische Akademie der Wissenschaften et al. Berlim, 1900-1922.

. Kritik der Urteilskraft. Org. de H. F. Klemme, Hamburgo, 2. ed., 2006.

. Kritik der reinen Vernunft. Org. de J. Timmermann, Hamburgo, 1998.

KLEMME, Heiner F. "Einleitung”. In: Immanuel Kant, Kritik der Urteilskraft. Beilage: Erste Einleitung in die Kritik der Urteilskraft. Org. de H. F. Klemme, XVII-CI, Hamburgo, 2006. 
KLEMME, Heiner F. "Kant und die Paradoxien der Kritischen Philosophie". In: KantStudien, 98 (2007), 40-56.

MCDOWELL, John. "Two Sorts of Naturalism". In: Mind, Value, and Reality, 1998, Cambridge (Mass), 167-197.

WATKINS, Eric. "Die Antinomie der teleologischen Urteilskraft und Kants Ablehnung alternativer Teleologien (§§ 69-71 e §§ 72-73)". In: Höffe, Ottfried (Org.). Immanuel Kant, Kritik der Urteilskraft. Berlim, 2008, p. 241-258.

\section{Traduções utilizadas}

KANT, I. Crítica da faculdade do juízo. Trad. de V. Rohden \& A. Marques. Rio de Janeiro: Forense Universitária, 1993.

Crítica da razão pura. Trad. de M. P. dos Santos e A. F. Morujão. Lisboa: Fundação Calouste Gulbenkian, 1985. 